\title{
An Exploratory Study of Consumers' Knowledge and Attitudes about Lignin-Based Sunscreens and Bio-Based Skincare Products
}

\author{
Nežka Sajinčič ${ }^{1}\left(\mathbb{D}\right.$, Oihana Gordobil ${ }^{1, *}$, Amy Simmons ${ }^{1}$ and Anna Sandak 1,2 \\ 1 InnoRenew CoE, 6310 Izola, Slovenia; nezka.sajincic@innorenew.eu (N.S.); \\ amy.simmons@innorenew.eu (A.S.); anna.sandak@innorenew.eu (A.S.) \\ 2 Natural Sciences and Information Technologies, Faculty of Mathematics, University of Primorska, \\ 6000 Koper, Slovenia \\ * Correspondence: oihana.gordobil@innorenew.eu
}

check for updates

Citation: Sajinčič, N.; Gordobil, O.; Simmons, A.; Sandak, A. An Exploratory Study of Consumers' Knowledge and Attitudes about Lignin-Based Sunscreens and Bio-Based Skincare Products. Cosmetics 2021, 8, 78. https:// doi.org/10.3390/cosmetics8030078

Academic Editor: Isabel Martins de Almeida

Received: 28 July 2021

Accepted: 24 August 2021

Published: 27 August 2021

Publisher's Note: MDPI stays neutral with regard to jurisdictional claims in published maps and institutional affiliations.

Copyright: (c) 2021 by the authors. Licensee MDPI, Basel, Switzerland. This article is an open access article distributed under the terms and conditions of the Creative Commons Attribution (CC BY) license (https:/ / creativecommons.org/licenses/by/ $4.0 /)$.

\begin{abstract}
Daily consumption of synthetic sunscreens is harmful to the environment and consumers' health, so greener alternatives need to be produced. Lignin is a multifunctional and widely available biopolymer that can replace several ingredients, but its dark color and low sun protection limit its perceived usefulness. With a survey made for this study, we explored the knowledge and attitudes of 230 consumers towards lignin-based sunscreen, their motives and barriers to purchase it, and how it relates to their environmental and health consciousness. Participants were also asked about their sunscreen habits, their familiarity with the environmental and health impacts of skincare, their perceptions of bio-based ingredients in general, and their skincare product purchasing decisions. Those who are more familiar with environmental issues have a positive attitude towards bio-based ingredients, are accustomed to purchasing more environmentally friendly skincare, and are likelier to be interested in a lignin product. Consumers are welcoming towards a natural, healthy, and environmentally friendly sunscreen alternative but are worried about the lower SPF. Because organic is perceived as luxurious, they are concerned about its price, and some are apprehensive about its pigmentation. While a lignin-based sunscreen at this stage of development is unlikely to take on the role of primary sunscreen on warm, sunny days, it may be more useful as a general-purpose, everyday product that can offer some protection, moisture, and coverage.
\end{abstract}

Keywords: attitude; bio-based ingredients; environmental concern; green cosmetics; health consciousness; human factors; knowledge; lignin sunscreen; preference; skincare

\section{Introduction}

The use of cosmetics and personal care products has grown exponentially across all genders in recent decades, reaching a global market value of USD 380.2 billion in 2019, which is expected to grow to USD 463.5 billion by 2027 [1]. The personal care market is largely driven by skin and sun care products aimed at beautifying, preventing skin from imperfections, and protecting skin against the damaging effect of ultraviolet (UV) rays.

Currently, chemical active ingredients in skin and sun care products are perceived to be of concern from both environmental and health perspectives. For instance, some preservatives, antioxidants, and UV filters have been shown to bioaccumulate in aquatic ecosystems and living organisms and to cause endocrine disruption, originating adverse effects on fecundity and reproduction in several organisms $[2,3]$. Therefore, there is an urgent need to develop innovative, environmentally friendly, and healthier alternatives to the current synthetic ingredients in skin and sun care formulations. Several researchers are already striving to replace fossil-based additives with bio-based alternatives, considering phytochemicals such as polyphenols and natural pigments (i.e., lycopene carotenoid) due to their protective properties against photodamage and skin aging for this purpose [4]. 
Lignocellulosic biomass has recently been recognized as a source of bio-based ingredients: ingredients derived in whole or in part from renewable (non-petroleum) materials, such as plants and animals. Recent research into the diverse functional and bioactive properties of lignin polymers has led to increased interest in this bio-sourced compound for skincare applications such as sunscreens [5]. Lignin is the only high molecular weight polyphenolic compound on Earth present in the cell walls of plants and trees. It is usually generated as an undervalued by-product from kraft-pulping operations, the global method for pulp manufacture, producing more than 100 million tons of kraft lignin annually worldwide [6]. The lignin structure contains a variety of functional groups capable of absorbing UV radiation. Unlike most chemical UV filters, lignin acts as a broad-spectrum sunblock, protecting against both UVA and UVB radiation [7]. It is also a non-toxic compound with antioxidant and antimicrobial properties relevant to skincare products [8]. Although the potential of lignin as a natural active ingredient is promising, there are still some technical limitations that hinder its high-value application in skincare, such as its dark brown color and low sun protection factor (SPF). Different types of lignin have been tested as an additive in pure creams, providing an SPF of no more than 10 by adding up to $10 \%$ lignin [7]. Recently, some strategies have been investigated, such as chemical modification and particle size reduction, which improved sun protection performance and color reduction [9]. However, further research is needed to achieve appropriate UV-blocking performance and avoid degradation during its service life.

Ultimately, it is the consumers who drive the market. As the public becomes increasingly aware of the environmental and health issues caused by the production and daily consumption of skincare and sunscreen products, greener alternatives appear to be a compelling option. However, when introducing any kind of novelty, it is not only external factors such as the product's functionality, price, or other features that matter, but human factors also play an important role [10]. While a lignin-based sunscreen may be a well-rounded replacement for several synthetic ingredients, it is not yet known how potential users would perceive such a product. For this reason, the study aimed to explore several psychological constructs that may be related to consumers' decision-making process and purchasing behavior regarding a sunscreen containing lignin in the context of other bio-based skincare products and people's sun-related behaviors.

\subsection{Sunscreens}

Before looking at people's views of lignin, we were interested in exploring their behaviors, knowledge, and attitudes regarding sunscreens. In general, studies have shown that sunscreen use is still low. While people with lighter skin types use sunscreen more often, men, people of color, those with lower education levels or lower incomes, and individuals with less sun-sensitive skin report using sunscreen less frequently and with lower SPF [11,12]. Similarly, another study reported that women were more likely to use sunscreen, reapply it during the day, and reapply it after swimming, but there were no differences between genders in skin health-related knowledge and tanning motives [13]. People are generally well informed about the effects of sun exposure, have positive attitudes towards sun protection, and use sunscreen with an SPF of at least 15 [14]. When participants were asked what prevents them from using sunscreen frequently, they often cited aesthetic and sensory properties of the sunscreen, suggesting that how the product looks and feels is important to consumers [15].

\subsection{Attitude, Knowledge, and Behavior in Relation to Green Skincare Products}

Researchers have long paid attention to consumer attitudes, defined as the extent to which a person has a favorable or unfavorable evaluation of an object, behavior, or concept [16] because of their propensity to predict and influence behavior [17]. Individuals who have a positive attitude toward a product, its ingredients, or its meaning are more likely to purchase and use the product than those who are apprehensive towards it. 
Attitude towards the environment or the tendency to evaluate the natural environment with a certain level of (un)favorableness [18] has been extensively researched and has been shown to be a critical factor in predicting pro-environmental behavioral intentions [19]. Health consciousness, which represents a person's awareness, concern, and willingness to do something about one's health [20], has also begun to attract attention as a potential determinant of greener consumption [21], as people perceive organic products as a healthier choice [22]. For instance, research has shown that people who are more conscious about both the environment and their own health are likelier to have a more positive attitude and purchase eco-friendly, organic, and self-protective products [23-28]. Literature focusing on green cosmetics and skincare products in particular shows similar results; concerns about the environment and human health predicted a more positive attitude towards green skincare, which in turn predicted purchase intention $[21,29,30]$. However, some studies report that attitudes toward health and the environment are not strong enough motives to influence consumers' purchase intention and attitudes toward eco-friendlier products [31-33].

Furthermore, an extensive review on green purchasing behavior found that knowledge about environmental issues and eco-products is the most studied variable and one of the most influential factors affecting purchase intention and behavior, both directly and indirectly, by influencing consumers' attitudes [31,34-36]. A recent study showed that while there were no differences between males and females in purchase intention and familiarity with environmental issues, female consumers showed more concern for the environment and were more familiar with eco-products [35].

However, how do consumers view green cosmetics and what are their main motivations for buying them? A qualitative study examining knowledge and attitudes towards green cosmetics among UK female consumers found that participants defined green cosmetics as safe, containing natural ingredients, and environmentally friendly. They not only considered the environmental impact of cosmetics' ingredients but also their packaging and production process. They also showed that strong supportive attitudes towards green cosmetics were associated with better familiarity with green cosmetics. However, they mostly associated green cosmetics with luxury and a higher price [37]. Another study using a word association approach showed that Japanese women perceived plant-based cosmetics as gentle and safe to use but also expensive and having slower, gradual results, with some even concerned about possible adverse effects [38]. Price was found to be a main barrier to buying organic cosmetics [33]. A survey that looked at the motivations for buying organic cosmetics revealed three main motives, in this order: personal health benefits, product quality, and environmental protection [39].

\subsection{Objectives}

Based on all these findings, it is essential to explore people's familiarity with and attitudes towards a lignin-based sunscreen, and this is imperative before it is launched on the market. To the best of the authors' knowledge, there are no studies investigating people's relationship with lignin-based sunscreens, so our main objective was to explore how potential consumers perceive such a product, whether they are familiar with lignin at all, whether they would be willing to purchase it, and what their drivers and barriers to doing so are. We also wanted to learn more about people's sunscreen usage patterns and their views on bio-based ingredients, skincare, the environment, and health, which may help inform the design process of a lignin-based sunscreen and how to more specifically promote healthier sun-related behaviors. Although the study is primarily exploratory in nature, based on the literature, we expect that greener purchasing choices and willingness to purchase lignin are positively associated with familiarity and supportive attitudes toward bio-based ingredients for skincare, the environment, and health consciousness. 


\section{Materials and Methods}

\subsection{Participants}

A convenience sample of 230 people completed the survey in full $(M=34.99$ years, $S D=11.35,72.17 \%$ female, 25.22\% male; see (Table S1). Participants belonged predominantly to the authors' social networks. To be eligible, respondents had to be of legal age and able to understand and write English or Slovenian. A total of $138(60 \%)$ respondents filled out the survey in Slovenian. A total of $93.04 \%$ of the subjects were European (156 or $67.83 \%$ participants indicated their citizenship as Slovenian, 20 or $8.70 \%$ were from Spain), 8 or $3.48 \%$ were from North America, 6 or $2.61 \%$ were from Asia, 4 participants did not disclose their citizenship, and 1 subject each was from Australia and South America (0.43\%). Participation was voluntary and subjects received no compensation.

\subsection{Ethical Consideration}

After a welcome message with a brief explanation of the study, participants had the opportunity to read an informed consent form (Document S2), which informed them of the purpose and procedure of the study, their rights, risks, and data management. Before being led to the survey, subjects had to confirm that they had read the document and understood its contents by ticking the option, "Yes, I agree with collecting my data".

\subsection{Materials}

The cross-sectional survey was designed specifically for this study based on an extensive literature review. The constructed instrument consisted of 26 questions (1 open-ended) divided into 5 sections: (a) use of skincare and sunscreen products (7 questions), (b) attitude towards skincare and sunscreen products $(2),(\mathrm{c})$ knowledge and perception of (bio-based) ingredients and their effects (7), (d) attitude towards lignin (3), and (e) socio-demographic data (7).

Most questions had multiple choices or a 5-point Likert-type rating scale (e.g., never to always, strongly disagree to strongly agree). To reduce respondent confirmation bias and increase the construct validity of the scale, some items were phrased inversely [40] and all questions contained at least one of the following response options: "Do not know," "Not relevant" (or equivalent), and "Prefer not to answer."

The first section asked about users' behaviors, preferences, and experiences. First, respondents rated how frequently they use various skincare products in general and how frequently they use and reapply sunscreen in specific conditions. In terms of sunscreens, respondents were asked to indicate the SPF they use on their face and body on sunny and cloudy days and whether their sunscreen provides protection from UVA, UVB, or both types of radiations. In addition, respondents indicated whether they prefer a cream or lotion consistency and whether they have ever had an adverse reaction to a skincare product.

Next, from 10 listed properties of sunscreen (e.g., price, brand, novelty), respondents had to select those relevant to them when buying a product and rank them by importance. In the following question, they rated their level of agreement with seven statements that covered their attitudes toward skincare and sun-related concepts.

The third section of the survey consisted of seven types of questions. The first included 11 statements about perceptions of chemicals and their effects and attitudes toward skincare and health. The next allowed respondents to indicate whether they had ever heard that synthetic ingredients in sunscreens were harmful to marine life and to choose the sources of this information (e.g., TV, friends and family, research institute). They were then asked if they avoid any ingredients in skincare products; how familiar they are with lignin, bio-based ingredients, biopolymers, and the information that natural biopolymers can be obtained from renewably sourced leftover materials from industry; and if they would like to know more about bio-based ingredients for skincare products. The next question contained 11 pairs of words (e.g., traditional-innovative, unsafe-safe, affordableluxurious); participants had to choose one word from the pair that they associated more with the term "bio-based". The section concluded with ten statements about people's 
perceptions of bio-based ingredients in skincare, which respondents rated based on their level of agreement.

The following block of questions explored the subjects' attitudes towards lignin and its use in skincare. Similar to the previous example, participants chose one word from six pairs of words that they felt was more related to lignin. Based on a brief description of lignin, its advantages and disadvantages, respondents then rated their willingness to purchase a skincare product containing this ingredient and were asked to describe their reasons for doing so with an open-ended question.

Finally, sociodemographic data were collected, including age, gender, education level, occupation, country of residence, and subjective socioeconomic status. Using a description and picture, participants also indicated their skin type.

Two versions of the survey were developed, one in English (see Document S1) and one in Slovenian. The survey was first developed and reviewed in English with the help of a native speaker. Then, two native Slovenian speakers with a good command of English and the terminology of the survey content contributed to the translation of the instrument into Slovenian. One translated the survey from the source language to the target language and the other compared and reviewed the two versions for inconsistencies to assess the adequacy of the Slovenian instrument.

\subsection{Data Collection and Analysis}

The survey was created using the $1 \mathrm{ka}$ survey tool (Faculty of Social Sciences, University of Ljubljana, Ljubljana, Slovenia) and distributed online. Data collection took place from January to April 2021 by distributing links to the survey via Facebook, LinkedIn, Twitter, Messenger, Slack, and email. Subjects from the authors' social networks were further encouraged to recruit other participants by sharing the link to the survey on their social networks. The average time to complete the survey was $14 \mathrm{~min}$.

Data analysis was performed using R 4.0 (A Language and Environment for Statistical Computing, http:/ / www.r-project.org/index.htm 1 (accessed on 29 April 2021) and jamovi 1.6 (The Jamovi Project, https: / / www.jamovi.org (accessed on 29 April 2021). By averaging scores on related single items, we constructed more general constructs. A total of 6 items were used to construct a total measure of Skincare use $(\omega=0.83), 6$ for Sunscreen use $(\omega=0.89), 11$ items Attitude $(\omega=0.70), 4$ for Buying behavior $(\omega=0.79), 11$ for Knowledge $(\omega=0.48)$, and 3 for Familiarity with bio-based ingredients $(\omega=0.79)$ (Table S2). Prior to analysis, the inverted items were reverse coded. Ranked answers were also reverse coded to ensure that the most important attributes received the highest scores. Open-ended responses were sorted into categories by the first author based on content themes and checked by the other authors. A response with more than one theme was sorted into all relevant categories.

In addition to descriptive statistics (frequencies, measures of central tendency, and variability), Mann-Whitney U test and Spearman $r_{s}$ correlations were used throughout the analysis because the assumptions of parametric tests were not met for most of the outcomes analyzed. Due to multiple comparisons, the likelihood of a Type I error (incorrectly rejecting a null hypothesis at a statistically significant level) is increased. Since this study is exploratory, no correction was used to mitigate false positives, so caution should be used when interpreting the results.

\section{Results}

\subsection{Sunscreen Use and Preferences}

To understand the needs and behaviors of potential users, we first asked them about their sunscreen habits and preferences. The most frequently used skincare products are face moisturizers and cleansers, followed by sunscreen for the face and body, while the least used products were body moisturizers and anti-ageing products (Table 1). Less than $9 \%$ of the respondents reported never using sunscreen for their face or body, and $31 \%$ use sunscreen on their face rarely, $27 \%$ sometimes, $18 \%$ often, and $15 \%$ more than $90 \%$ of the 
time. On the other hand, only $6 \%$ use body sunscreen most of the time, while $40 \%$ wear it rarely, $33.5 \%$ sometimes, and $12 \%$ often.

Table 1. Descriptive statistics of items and total score for skincare and sunscreen use.

\begin{tabular}{|c|c|c|c|c|}
\hline & $M$ & $S D$ & $M d n$ & $I Q R$ \\
\hline Frequency of Using Skincare Products & 2.92 & 0.96 & & \\
\hline Moisturizer on the face & 3.65 & 1.49 & 4 & $2-5$ \\
\hline Cleanser & 3.33 & 1.62 & 4 & $2-5$ \\
\hline Sunscreen on the face & 3.01 & 1.20 & 3 & $2-4$ \\
\hline Sunscreen on the body & 2.66 & 0.99 & 3 & $2-3$ \\
\hline Moisturizer on the body & 2.55 & 1.19 & 2 & $2-3$ \\
\hline Repair or anti-ageing products (antioxidants, serums, exfoliators, etc.) & 2.31 & 1.39 & 2 & $1-3$ \\
\hline Frequency of Using Sunscreen Products in Specific Conditions & 2.92 & 1.01 & & \\
\hline At the beach & 4.38 & 1.08 & 5 & $4-5$ \\
\hline On warm sunny days & 3.51 & 1.26 & 4 & $3-4$ \\
\hline During recreation (e.g., jogging, cycling, walking, hiking) & 3.00 & 1.31 & 3 & $2-4$ \\
\hline During outdoor domestic chores (e.g., lawn mowing, snow removal, gardening) & 2.29 & 1.31 & 2 & $1-3$ \\
\hline During outdoor job-related tasks (e.g., construction work, delivery) & 2.12 & 1.37 & 2 & $1-3$ \\
\hline On cloudy days & 2.05 & 1.20 & 2 & $1-3$ \\
\hline
\end{tabular}

When asked about the use of sunscreen in different conditions, subjects reported using it most often at the beach and on warm sunny days. While $10 \%$ said they never or rarely use sunscreen at the beach, nearly $85 \%$ use it always or often. Similarly, almost $60 \%$ wear sunscreen often or always on warm sunny days, but $21 \%$ rarely or never do. On the other hand, $70 \%$ never or rarely wear sunscreen on cloudy days, and $62 \%$ do so when performing outdoor work or domestic activities.

People reapply their sunscreen most often at the beach and in the mountains, but least often on normal days (Figure 1).

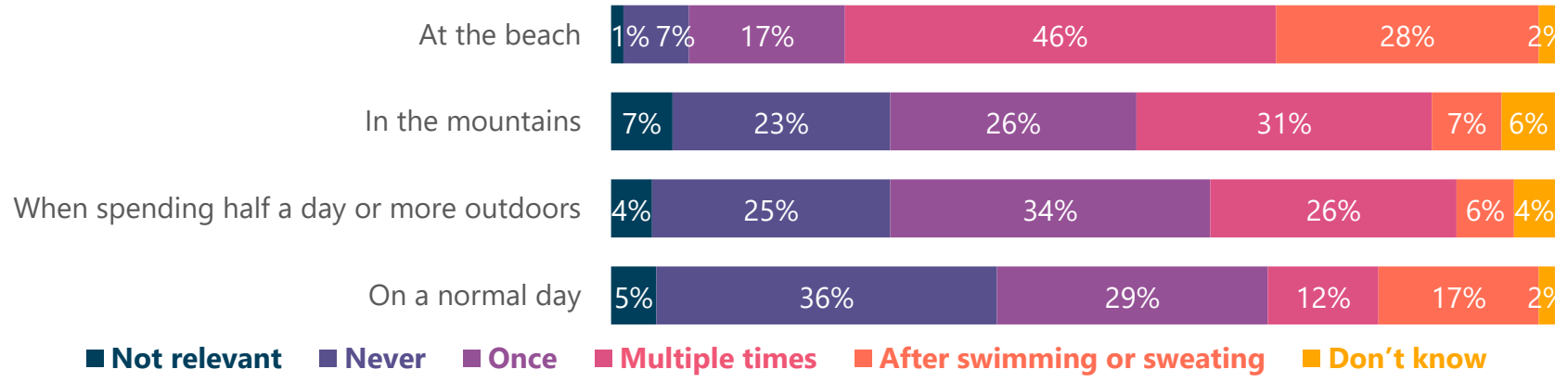

Figure 1. Frequency of sunscreen reapplication in various circumstances.

We also asked respondents about the SPF they use (Figure 2). While about 3\% of participants did not know what SPF they generally use, on warm and sunny days, people preferred sunscreen with an SPF of 50 or higher for the face. While on cloudy days, the majority of respondents did not use sunscreen, people preferred an SPF of at least 15 for both their face and body in a variety of circumstances. 
On the face on warm sunny days

On the face on cloudy days

On the rest of the body on warm sunny days

On the rest of the body on cloudy days

\section{$7 \% \quad 5 \%$} $21 \%$ $28 \%$ $36 \%$

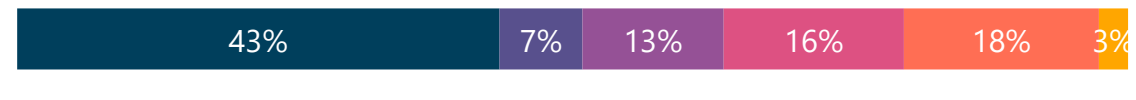

\section{$10 \% \quad 7 \%$}

$28 \%$

$28 \%$

$24 \%$

$\begin{array}{lll}6 \% & 10 \% & 16 \%\end{array}$

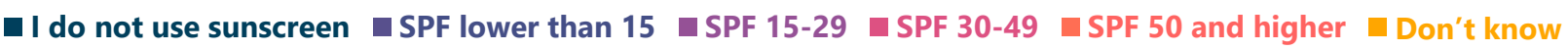

Figure 2. SPF used in various circumstances.

When asked about the type of protection their sunscreen usually has, more than a third (34.5\%) did not know, no one chose UVB, 5.4\% indicated UVA, and 60.1\% said their sunscreen provided protection from both UVA and UVB rays.

Participants were also asked about their preferred type of sunscreen. A total of $50.9 \%$ indicated a preference for lotion sunscreens, $29.7 \%$ preferred creams, $17.1 \%$ had no preference, and $2.3 \%$ did not know if they have a preference.

One-third of participants reported avoiding certain ingredients in their skincare. Parabens (15 participants) and perfumes (13) were mentioned most frequently, followed by aluminum and sodium laureth sulfate (6); alcohol, oxybenzone, petroleum, and titanium dioxide (5); microplastics and silicones (4); and essential oils, formaldehyde, PEG, and sulphates (3). Other ingredients mentioned were animal-based ingredients, nanoparticles, non-natural ingredients, palm oil, and preservatives (2) and aloe vera, ammonium chloride, antiperspirants, chemicals in general, corticosteroids, EDTA, glycerol, glycerin, octocrylene, phthalates, pore-clogging ingredients, retinol, sulfuric acid, sun-protective filters in general, methicone, and triclosan (1).

A total of $13.9 \%$ of respondents reported having had an allergic or irritant reaction to a skincare product, while $3.5 \%$ did not know.

\subsection{Knowledge and Awareness Related to Sunscreen, Health, Environment, and Bio-Based Skincare}

Participants were asked to rate their level of agreement with 11 statements to find out how knowledgeable they were about sunscreen use, ingredients in skincare products, and their relationship to our health and environment. To ensure greater objectivity, the items were distributed across the survey, and four of them (marked with an *) were inverted, meaning they represented a false claim.

As Figure 3 shows, inaccurate items such as "Solar radiation is harmless" $(M=2.04$, $S D=1.37, M d n=1, I Q R=1-3)$, "Having a tan is healthy" $(M=2.23, S=0.92, M d n=2$, $I Q R=2-3)$, and "Chemicals from skincare products are harmless to ecosystems" ( $M=2.31$, $S D=1.23, M d n=2, I Q R=1-3$ ) had the highest levels of disagreement, meaning respondents recognized them as untrue. Participants most agreed with statements such as "Use of sunscreens can prevent sunburns, skin damage, skin ageing and skin cancer" $(M=4.44$, $S D=0.85, M d n=5, I Q R=4-5)$, "Chemicals can cause dermatological side effects" ( $M=4.25$, $S D=0.65, M d n=4, I Q R=4-5)$, "Synthetic UV filters, antioxidants and preservatives are common ingredients in skincare" $(M=4.09, S D=0.65, M d n=4, I Q R=4-5)$, and "Ingredients from skincare and sunscreen products are being continuously released into the environment" $(M=4.03, S D=0.80, M d n=4, I Q R=4-5)$. Participants appeared to be well informed about current guidelines and evidence on the relationship between skincare, sun care, human health, and the environment $(M=3.87, S D=0.39)$. However, almost half of the sample did not know that chemicals from skincare products have been detected in human fluids, such as urine, semen, breast milk, and the bloodstream $(M=3.86, S D=0.80$, $M d n=4, I Q R=3-4)$, indicating a knowledge gap. 


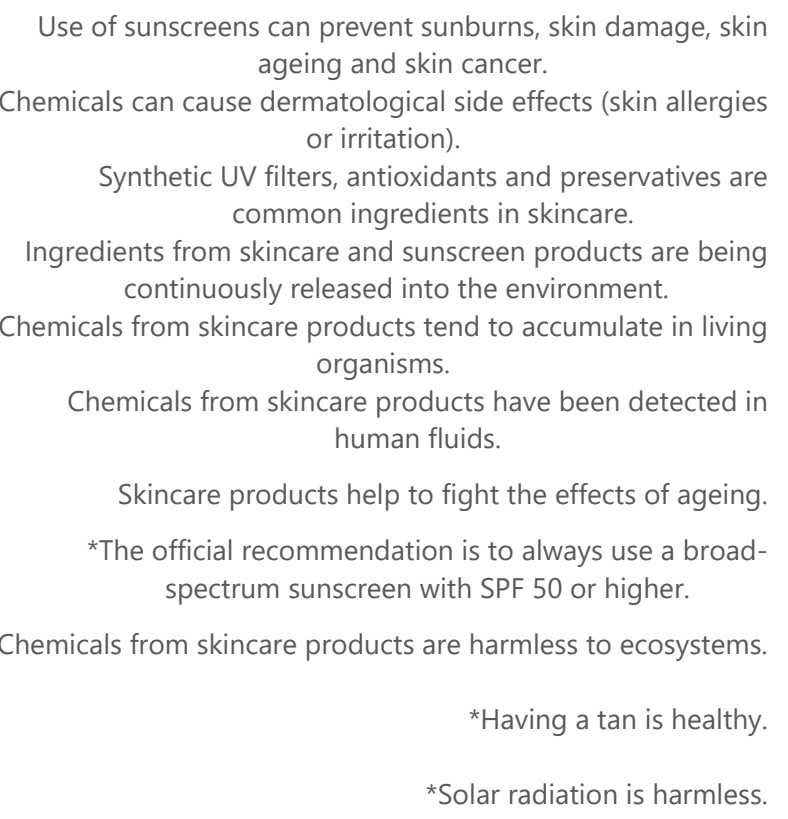

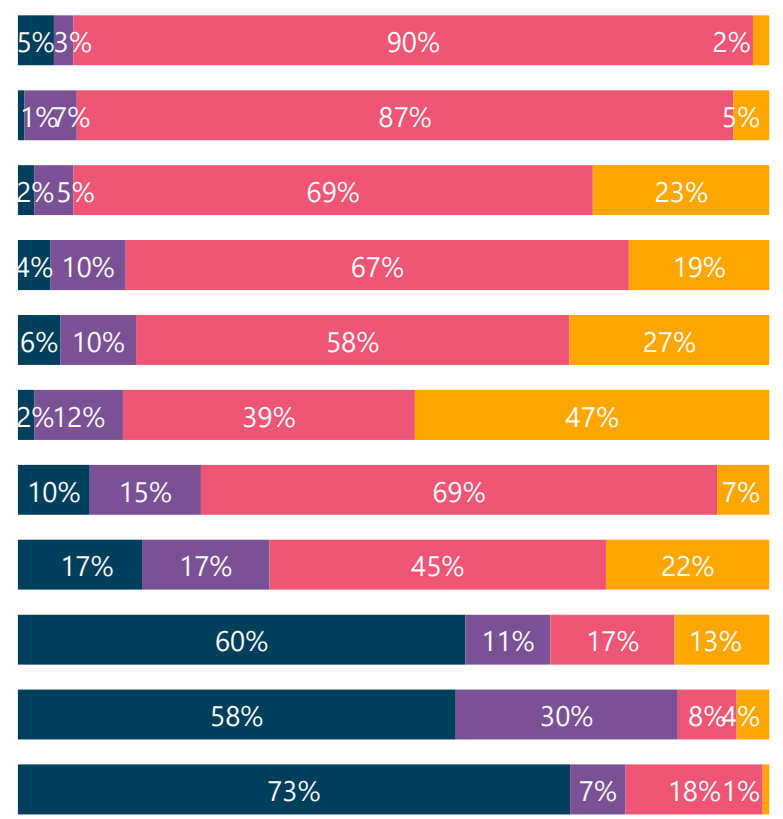

\section{a (Strongly) disagree $\quad$ Neither agree nor disagree $\quad$ (Strongly) agree $\quad$ Don't know}

Figure 3. Knowledge items with answer distribution from highest to lowest level of agreement ( ${ }^{*}$ represent a false claim).

Subjects were also asked if and where they have heard that research has shown that synthetic ingredients are harmful to corals and other marine life (Figure 4). A total of 63.9\% said they had known about this information. Most of them learned about it from social media $(f=73)$, television $(f=66)$, and researchers or research institutes $(f=65)$.

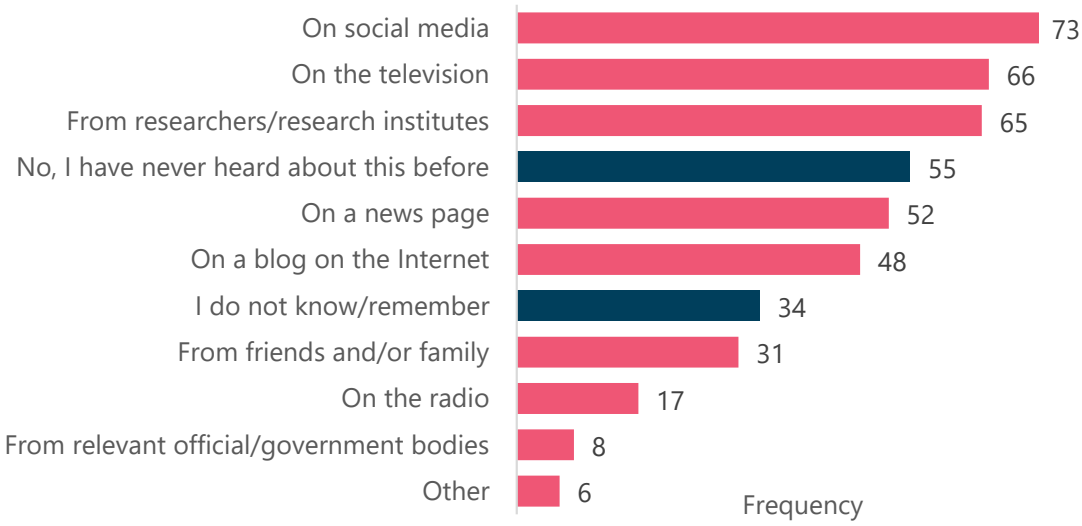

Figure 4. Frequency of reported source of information $(n=455)$.

More generally, participants rated their familiarity with (1) bio-based ingredients or substances of natural origin for skincare $(M=2.23, S D=0.61, M d n=2, I Q R=1-3)$; (2) the notion that natural biopolymers, defined as large molecules from plants or animals, can also be obtained from renewable sourced leftovers and waste from industry $(M=1.78$, $S D=0.77, M d n=2, I Q R=1-2)$; and (3) the fact that biopolymers from nature can be used as ingredients for skincare and sun protection products $(M=1.86, S D=0.76, M d n=2$, $I Q R=1-2)$. The majority of participants reported that they were not familiar with the topics (Figure 5), which may also be a consequence of using more technical terms in the items.

When asked if they would like more information about bio-based ingredients for skincare products, more than two-thirds answered yes $(68.7 \%), 18.3 \%$ were not interested, and $13 \%$ were unsure, conveying a general interest in the topic. 
Bio-based ingredients for skincare

Biopolymers from nature can be used as an ingredient for skincare and sun protection products

\begin{tabular}{|c|c|c|c|c|}
\hline $10 \%$ & \multicolumn{2}{|c|}{$56 \%$} & $31 \%$ & $3 \%$ \\
\hline & $33 \%$ & $37 \%$ & $20 \%$ & $10 \%$ \\
\hline & $38 \%$ & $32 \%$ & $19 \%$ & $11 \%$ \\
\hline
\end{tabular}

Natural biopolymers can be obtained from renewable sourced leftover and waste materials from the industry

Never heard about it I have heard about it $\quad$ I am familiar with the topic $\quad$ Don't know

Figure 5. Self-assessed familiarity with bio-based ingredients.

\subsection{Buying Behavior and Preferences for Bio-Based Skincare Products}

Next, we explored the sample's purchasing behavior and preferences for bio-based skincare products using four items (Figure 6). About $60 \%$ of the participants agreed or strongly agreed that they usually check the ingredients before buying products $(M=3.58$, $S D=1.15, M d n=4, I Q R=3-4)$ and that they are willing to pay more for a bio-based product $(M=3.64, S D=0.96, M d n=4, I Q R=3-4)$. About half of respondents tend to already buy natural skincare products $(M=3.44, S D=1.11, M d n=3.5, I Q R=3-4)$ and plan to do so in the future $(M=3.60, S D=0.94, M d n=4, I Q R=3-4)$. In general, at least half of the sample pays attention to the origin of ingredients when buying skincare products $(M=3.54, S D=0.85)$.

I am willing to pay more for a bio-based skincare product if it is free of chemicals.

I will buy skincare products containing mainly bio-based ingredients in the future.

I usually check the ingredients of the products when buying it.

I tend to buy skincare products with ingredients of natural origin.

\begin{tabular}{|cccc}
\hline $12 \%$ & $22 \%$ & $62 \%$ & $4 \%$ \\
\hline $9 \%$ & $29 \%$ & $50 \%$ & $12 \%$ \\
\hline $19 \%$ & $18 \%$ & $60 \%$ & $3 \%$ \\
\hline $18 \%$ & $30 \%$ & $48 \%$ & $3 \%$ \\
\hline & & & \\
\hline
\end{tabular}

\section{口 (Strongly) disagree $\quad$ Neither agree nor disagree $\quad$ (Strongly) agree $\quad$ Don't know}

Figure 6. Buying related items with answer distribution from highest to lowest level of agreement.

Respondents also ranked various attributes of sunscreens by their importance when deciding to buy the product. The most important deciding factors were quality, price, and texture, closely followed by natural ingredients (Figure 7). The least important qualities of sunscreens were their novelty, color, and packaging.

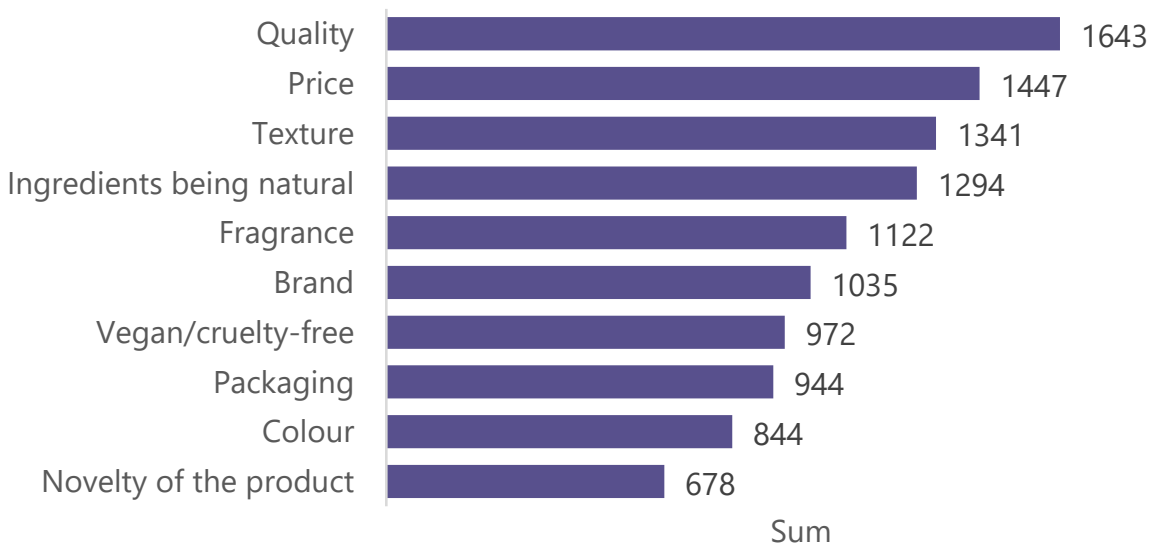

Figure 7. Sum of the ranked properties of sunscreen from most to least important. 


\subsection{Attitude towards Bio-Based Ingredients}

Eleven items were used to measure participants' attitudes towards bio-based ingredients, five of which represented an inclination towards naturally and sustainably sourced ingredients (Figure 8). Attitude towards bio-based ingredients, in general, was positive $(M=3.64, S D=0.47)$. The highest-rated items referred to the importance of ingredient sourcing and sustainable production $(M=4.42, S D=0.62, M d n=4, I Q R=4-5)$, valorization of agricultural waste as ingredients being innovative $(M=4.06, S D=0.86, M d n=4$, $I Q R=4-5)$, and the positive environmental impact of bio-based skincare products $(M=4.04$, $S D=0.85, M d n=4, I Q R=4-5)$. In contrast, participants agreed the least with the statement that they prefer conventional ingredients over bio-based ingredients $(M=2.12, S D=0.88$, $M d n=2, I Q R=2-3)$, being apprehensive towards skincare of brownish color $(M=2.35$, $S D=1.08, M d n=2, I Q R=2-3)$, and the inability of bio-based ingredients to replace synthetic ones $(M=2.38, S D=1.06, M d n=2, I Q R=2-3)$. Three-fourths of participants are worried about the environmental impact of synthetic ingredients $(M=3.99, S D=0.89$, $M d n=4, I Q R=4-5)$ but also perceive that bio-based skincare products are more expensive $(M=4.01, S D=0.69, M d n=4, I Q R=4)$. In addition, one-fifth of respondents did not know how bio-based ingredients compared to synthetic ones in terms of functionality ( $M=2.53$, $S D=0.96, M d n=3, I Q R=2-3)$.

In addition to the origin of the ingredients, a sustainable way of their production is also important.

Obtaining bio-based ingredients from agricultural waste is innovative.

\begin{tabular}{|cccc|}
\hline $5 \%$ & $91 \%$ & $3 \%$ \\
\hline $4 \%$ & $14 \%$ & $69 \%$ & $13 \%$ \\
\hline $3 \%$ & $16 \%$ & $74 \%$ & $7 \%$ \\
\hline $2 \%$ & $14 \%$ & $74 \%$ & $10 \%$ \\
\hline
\end{tabular}

The environmental impact of synthetic ingredients concerns me. healthier for my skin than products with synthetic ingredients. *Good functionality/performance is what matters, not the origin

*Artificially made/synthetic ingredients are more efficient than

*Plant-derived ingredients cannot replace synthetic ingredients.

Skincare products containing bio-based ingredients are of the ingredients. natural ingredients.

*I would not want to use skincare/suncare products that are brownish in colour.

*I prefer conventional chemical ingredients over bio-based ingredients.

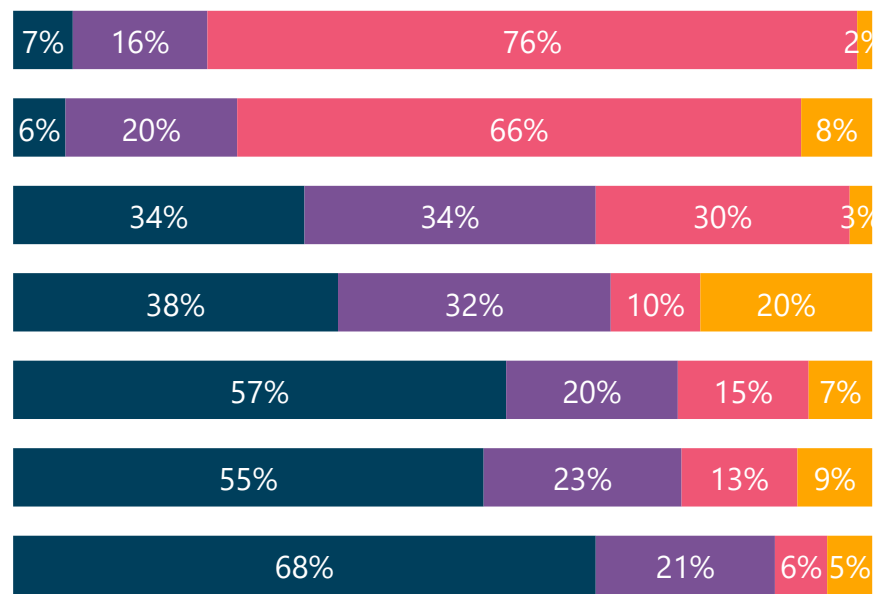

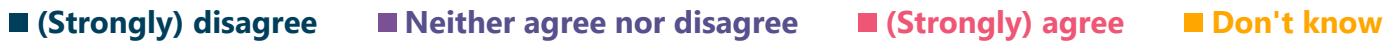

Figure 8. Attitude items with answer distribution from highest to lowest level of agreement (* represent a false claim).

We also checked participants' interest in skincare $(M=3.91, S D=1.00, M d n=4$, $I Q R=3-5)$, attitude towards their health $(M=3.84, S D=0.77, M d n=4, I Q R=3-4)$, and the environment $(M=4.37, S D=0.80, M d n=5, I Q R=4-5)$, using one item for each.

Subsequently, subjects were presented with pairs of conflicting adjectives and had to choose the one they associated more with the term "bio-based" (Figure 9). About half of the sample thinks of "bio-based" as traditional, while the other half thinks it is innovative. A similar proportion of respondents also believe that bio-based is better for the environment than for their own health. More than $85 \%$ of the participants consider bio-based to be 
safe, derived from plants, of lower toxicity, organic, environmentally friendly, high quality, and effective.

\begin{tabular}{|c|c|c|c|}
\hline Traditional & $53 \%$ & $47 \%$ & Innovative \\
\hline Better for my health & $48 \%$ & $52 \%$ & Better for the environment \\
\hline Wholly from biological materials & $44 \%$ & $56 \%$ & Partly from biological materials \\
\hline Affordable & $36 \%$ & $64 \%$ & Luxurious \\
\hline Non-effective & $13 \%$ & $87 \%$ & Effective \\
\hline Poor quality & $13 \%$ & $87 \%$ & High quality \\
\hline Depletion of natural resources & $12 \%$ & $88 \%$ & Environmentally friendly \\
\hline Non-organic & $5 \%$ & $95 \%$ & Organic \\
\hline Higher toxicity & $4 \%$ & $96 \%$ & Lower toxicity \\
\hline Derived from animals & $4 \%$ & $96 \%$ & Derived from plants \\
\hline Unsafe & $3 \%$ & $97 \%$ & Safe \\
\hline
\end{tabular}

Figure 9. Proportion of selected adjectives for "bio-based".

\subsection{Attitude towards Lignin and Lignin-Based Sunscreen}

Finally, we were interested in how familiar participants were with lignin and how they would perceive a lignin-based sunscreen. First, 39\% said they had never heard of lignin before the study, $26 \%$ said they had heard of it but did not know much about it, $26 \%$ were familiar with it, and $9 \%$ were not sure.

Figure 10 shows the selection of adjectives that participants felt best represented lignin. More than $80 \%$ of subjects perceive lignin as being derived from plants, safe, renewable, and of natural origin, and more than $60 \%$ believe it is affordable and industrially available.

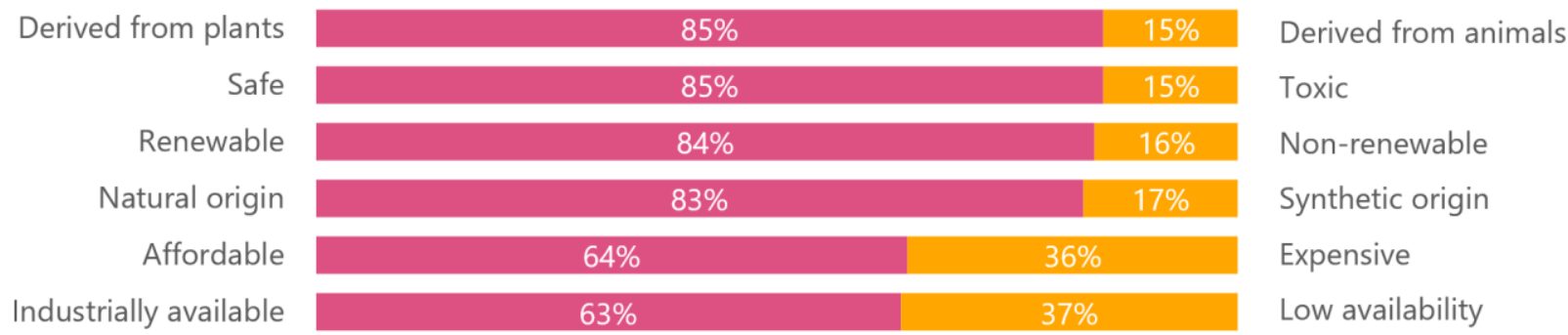

Figure 10. Proportion of selected adjectives for "lignin".

In the final part of the study, participants were presented with a brief description of lignin, its production, and the properties of a sunscreen that would contain this ingredient and were asked if they would purchase such a product. While $3.5 \%$ would not buy a lignin-based sunscreen, and $2.6 \%$ were unsure, $18.3 \%$ said "maybe", $23.5 \%$ said "probably", and $52.2 \%$ would buy it. An open-ended question collected participants' reasons for their decision and gathered 169 responses, which were coded into categories. Generally, the responses fell into two groups-reasons to buy (231 responses) and reasons not to buy (90 responses). Both include six general categories, which are later divided into more specific categories (Table 2). 
Table 2. Categories of responses to "Can you briefly describe your thoughts and reasons for (not) wanting to buy this product?".

\begin{tabular}{|c|c|c|c|c|c|}
\hline \multicolumn{3}{|c|}{ Reasons to Buy } & \multicolumn{3}{|c|}{ Reasons Not to Buy } \\
\hline Broad Category & Specific Category & $f$ & Broad Category & Specific Category & $f$ \\
\hline \multirow{3}{*}{ Sustainability } & Protects the environment & 54 & Performance & SPF too low & 35 \\
\hline & $\begin{array}{l}\text { Natural, bio-based, a substitute for } \\
\text { synthetic materials }\end{array}$ & 47 & \multirow{3}{*}{ Color } & $\begin{array}{c}\text { Cast when applied to skin, may look } \\
\text { uneven }\end{array}$ & 13 \\
\hline & Plant-based, vegan & 5 & & Color may stain clothes & 6 \\
\hline \multirow{4}{*}{ Human health } & Contributing to a good cause & 1 & & The color of the cream is unpleasant & 5 \\
\hline & Better for my health & 20 & \multirow{3}{*}{$\begin{array}{c}\text { Need } \\
\text { additional } \\
\text { information }\end{array}$} & $\begin{array}{l}\text { Need more information from } \\
\text { reputable sources }\end{array}$ & 6 \\
\hline & Safe & 11 & & $\begin{array}{l}\text { Distrust in the extraction methods } \\
\text { and substances }\end{array}$ & 4 \\
\hline & $\begin{array}{l}\text { Better alternative to mineral filters, } \\
\text { nanotechnology, preservatives }\end{array}$ & 6 & & $\begin{array}{l}\text { Need other people's } \\
\text { ratings/recommendations }\end{array}$ & 1 \\
\hline \multirow{3}{*}{ Innovation } & $\begin{array}{c}\text { Innovative utilization of leftovers and } \\
\text { by-products }\end{array}$ & 16 & \multirow{2}{*}{$\begin{array}{c}\text { Product's } \\
\text { characteristics }\end{array}$} & Suitability for skin & 10 \\
\hline & Wide availability & 8 & & Unpleasant smell & 1 \\
\hline & Novel, "cool" & 5 & Price & Too expensive & 5 \\
\hline \multirow{2}{*}{ Performance } & Good performance, broad-spectrum & 25 & No interest & Does not care about sunscreen & 4 \\
\hline & Longer shelf life & 1 & & & \\
\hline \multirow{2}{*}{ Color } & Does not care about the cream color & 15 & & & \\
\hline & Brown color is even better & 4 & & & \\
\hline Price & If the price is right & 13 & & & \\
\hline
\end{tabular}

Sustainability reasons were most frequently cited as a motive for purchasing a ligninbased sunscreen (107 responses). Protecting the environment and substituting synthetic ingredients with bio-based and vegan alternatives were seen as major benefits; one respondent even mentioned that buying such a product would make them feel like they were contributing to a good cause.

Another important category of responses can be summarized as caring for our health (37). People believed that a lignin-based sunscreen would be better for their health and thought it was safer; one participant specifically mentioned that they trusted the product if it was approved by the European Union. Some consider it a great alternative to several controversial ingredients such as mineral filters, preservatives, and nanoparticles:

"... I have used less and less sunscreen in recent years, as I believe that modern nanoparticle creams harm our skin more than sun radiation. With a product like this I might change my habits."

Twenty-nine participants were intrigued by the innovation aspect of the sunscreen and found utilizing the widely available industry leftovers and by-products to be innovative, "cool", and something new and original. One participant went further and wrote:

"Additional use of by-products should be the standard."

Twenty-six people cited the product's performance as an incentive to buy, specifically that lignin is a broad-spectrum sun-blocker, antioxidant, and also a preservative, which means it could have a longer shelf life. Another theme that emerged among the responses was the sunscreen's color (19). While some stated that they would not mind the cream's color, others said that a brownish color was actually better, as it can make the skin look tanned.

In the last class of responses, the importance of price was cited. Some felt that a $20-25 \%$ increase in price was justifiable, but others expected these products to be the same or even lower in price than traditional sunblocks since lignin is a by-product.

On the other hand, some participants were skeptical about the potential of ligninbased sunscreens. Most of them were concerned about the low SPF and indicated that it 
would have to be higher $(30,50, \mathrm{PA}++++)$ for them to consider buying the product ( 35 responses), especially for people with fair skin. As one respondent put it:

"I would definitely buy this product if it would protect me from UV rays.... However, the low SPF would be a reason not to buy it. I am prone to sunburns, so my skin requires higher SPF. Succeeding in improving SPF would definitely make me more interested in the product."

Three participants elaborated on this, saying that they would not use a lignin-based sunscreen at the beach, but would consider wearing it on a less sunny day around town, especially if sun protection was not its main or only purpose:

"If it is a product that has an additional purpose of sun protection (but it is not its main purpose), I might consider it. It seems to me that the protective factor is too small."

One parent also pointed out that the low SPF was not suitable for children:

"Due to the low protection factor, I would use it for myself, because I don't have such sensitive skin, and for my son, who has sensitive skin and is exposed to the sun longer due to sports, I would like it to have higher protection."

Twenty-four participants highlighted the brownish color of the cream as one of the main reasons why they would not buy a lignin sunscreen. While most of them were concerned that it would look uneven and leave a cast on their skin, others thought it would stain their clothes. Five participants specifically mentioned that they did not like the pigmentation of the product itself; one said it reminded them of feces, and one said they would only consider the cream if it was light brown.

Another portion of respondents felt they did not have enough information to make a decision. Some would wait for additional research and long-term data from reputable institutions; one also expressed interest in hearing other people's reviews and recommendations before trying it for themselves. In addition, some mentioned that they would be suspicious of the sustainability of lignin extraction or the methods used to achieve a higher SPF. In the words of one participant:

“... one ingredient does not influence my purchasing decision. INCI (International Nomenclature of Cosmetic Ingredients) doesn't tell me much because it matters how the whole formula was designed. In addition, natural/biological origin does not mean greater sustainability, as it is necessary to look holistically at how it is with the extraction of substances, storage, formulation, stabilization, etc."

One notable reason people had concerns about purchasing the lignin-based product is the higher price, especially compared to other products with natural ingredients, and worries that it would not be suitable for their skin, citing issues such as pore-clogging, excessive sweating, skin not being able to "breathe", a potential allergen, or an unpleasant odor. Finally, some individuals indicated that they would not purchase the sunscreen because they were not interested in sun care in general.

Overall, the findings from the open-ended question can be succinctly summarized by this participant's comment:

"... I am excited about healthier and environmentally friendly products, but functionality and big differences in price come first."

\subsection{Relationships}

Finally, we aimed to explore the associations between different constructs (Table 3). The significant relationships ranged from weak to moderate. While some of them were expected, such as a positive link between attitudes towards the environment and bio-based ingredients $\left(r_{\mathrm{s}}=0.46 p<0.001\right)$, between frequency of skincare and sunscreen use $\left(r_{\mathrm{s}}=0.58\right.$ $p<0.001)$, and between interest in skincare and skincare $\left(r_{\mathrm{s}}=0.50 p<0.001\right)$ and sunscreen use $\left(r_{\mathrm{S}}=0.26 p<0.001\right)$, some correlations, or lack thereof, were more surprising. 
In general, more health-conscious respondents were more interested in skincare $\left(r_{\mathrm{S}}=0.29 p<0.001\right)$ and were also more likely to use sun care products $\left(r_{\mathrm{S}}=0.20 p=0.003\right)$. Participants who were more familiar with the use and production of bio-based products were also more likely to have positive attitudes toward the environment $\left(r_{\mathrm{s}}=0.24 p<0.001\right)$ and bio-based ingredients in skincare $\left(r_{\mathrm{s}}=0.27 p<0.001\right)$.

People were likelier to engage in environmentally friendlier purchasing behaviors in terms of skincare if they had a positive attitude towards bio-based ingredients $\left(r_{\mathrm{S}}=0.52\right.$ $p<0.001)$ and the environment $\left(r_{\mathrm{s}}=0.37 p<0.001\right)$, avoided specific ingredients $\left(r_{\mathrm{S}}=0.31\right.$ $p<0.001)$, and were more familiar with bio-based ingredients in general $\left(r_{\mathrm{s}}=0.28 p<0.001\right)$.

As predicted, intention to purchase bio-based skincare in the future is most strongly associated with prior green purchasing behavior $\left(r_{\mathrm{s}}=0.57 p<0.001\right)$ and a positive attitude towards bio-based ingredients $\left(r_{\mathrm{s}}=0.63 p<0.001\right)$. Individuals who are more likely to intend to buy greener in the future are more health- $\left(r_{\mathrm{s}}=0.20 p<0.001\right)$ and environmentally $\left(r_{\mathrm{S}}=0.35 p<0.001\right)$ conscious, have an interest in skincare $\left(r_{\mathrm{S}}=0.24 p<0.001\right)$ and bio-based products $\left(r_{\mathrm{s}}=0.28 p<0.001\right)$, and are more likely to avoid certain ingredients $\left(r_{\mathrm{s}}=0.23\right.$ $p<0.001)$.

A similar trend can be observed with lignin. Individuals who have made more environmentally conscious purchasing decisions in the past $\left(r_{\mathrm{S}}=0.29 p<0.001\right)$ and intend to do so in the future $\left(r_{\mathrm{s}}=0.31 p<0.001\right)$ are more likely to purchase a ligninbased sunscreen, as are individuals with more positive attitudes toward the environment $\left(r_{\mathrm{s}}=0.26 p<0.001\right)$ and other bio-based ingredients $\left(r_{\mathrm{s}}=0.43 p<0.001\right)$. There were no significant associations between wanting to try a lignin-based sunscreen and concern for health $\left(r_{\mathrm{s}}=-0.04 p=0.548\right)$ or interest in skincare $\left(r_{\mathrm{s}}=-0.06 p=0.340\right)$. The more people know about lignin, the more likely they are to buy a product containing it $\left(r_{\mathrm{S}}=0.24\right.$ $p<0.001$ ), but familiarity with lignin itself is more pronounced among those who know more about bio-based ingredients $\left(r_{\mathrm{s}}=0.54 p<0.001\right)$, have a positive attitude toward them $\left(r_{\mathrm{S}}=0.15 p=0.027\right)$, buy greener options $\left(r_{\mathrm{S}}=0.22 p=0.001\right)$, and will do so in the future $\left(r_{\mathrm{S}}=0.20 p=0.008\right)$.

In terms of socio-demographics, participants with higher education are more familiar with lignin $\left(r_{\mathrm{s}}=0.37 p<0.001\right)$ and bio-based ingredients, their production from industrial waste, and their use in skincare $\left(r_{\mathrm{S}}=0.28 p<0.001\right)$. People with darker skin types use less sunscreen than people with lighter skin $\left(r_{\mathrm{s}}=-0.25 p<0.001\right)$.

Table 3. Spearman $r_{s}$ correlations.

\begin{tabular}{|c|c|c|c|c|c|c|c|c|c|c|c|c|}
\hline & FL & BL & Know & FBB & PB & PI & BBA & HA & EA & SI & SU & SunU \\
\hline Familiarity lignin & - & & & & & & & & & & & \\
\hline Buy lignin & $0.24 * * *$ & - & & & & & & & & & & \\
\hline Knowledge & -0.08 & 0.14 * & - & & & & & & & & & \\
\hline Familiarity bio-based & $0.54 * * *$ & $0.13 *$ & -0.10 & - & & & & & & & & \\
\hline Purchase behavior & $0.22 * *$ & $0.29 * * *$ & $0.15 *$ & $0.28 * * *$ & - & & & & & & & \\
\hline Purchase intention & $0.20 * *$ & $0.31 * * *$ & 0.13 & $0.28 * * *$ & $0.57 * * *$ & - & & & & & & \\
\hline Bio-based attitude & $0.15 *$ & $0.43^{* * *}$ & $0.27 * * *$ & 0.16 * & $0.52 * * *$ & $0.63^{* * *}$ & - & & & & & \\
\hline Health attitude & 0.06 & 0.04 & 0.03 & 0.13 * & $0.17^{*}$ & $0.20 * *$ & 0.06 & - & & & & \\
\hline Environment. attitude & 0.05 & $0.26 * * *$ & $0.24 * * *$ & 0.09 & $0.37 * * *$ & $0.35^{* * *}$ & $0.46 * * *$ & 0.11 & - & & & \\
\hline Skincare interest & -0.04 & 0.06 & 0.04 & 0.09 & $0.20 * *$ & $0.24^{* * *}$ & 0.03 & $0.29 * * *$ & 0.07 & 一 & & \\
\hline Skincare use & $-0.15 *$ & -0.08 & 0.03 & -0.05 & 0.03 & 0.03 & -0.09 & $0.24 * * *$ & -0.05 & $0.50 * * *$ & - & \\
\hline Sunscreen use & -0.07 & -0.08 & 0.05 & 0.04 & 0.08 & 0.00 & -0.06 & $0.20 * *$ & 0.02 & $0.26 * * *$ & $0.58 * * *$ & - \\
\hline Ingredient avoidance & -0.07 & 0.10 & $0.20 * *$ & 0.01 & $0.31 * * *$ & $0.23 * * *$ & 0.13 & 0.06 & $0.18^{* *}$ & $0.18^{* *}$ & $0.15 *$ & $0.22 * * *$ \\
\hline
\end{tabular}

Note. Significant results in bold. ${ }^{*} p<0.05,{ }^{* *} p<0.01,{ }^{* * *} p<0.001$. FL-familiarity lignin, BL-buy lignin, Know-knowledge, FBBfamiliarity bio-based, PB — purchase behavior, PI—purchase intention, BBA—bio-based attitude, HA-health attitude, EA—environmental attitude, SI—skincare interest, SU—skincare use, SunU—sunscreen use.

We also tested for possible differences between participants identifying as female and male using a Mann-Whitney $U$ test (Table 4). Five undisclosed respondents and one non-binary respondent were not included in this analysis because they were too few to form a comparable group. 
Table 4. Significant differences between subjects who identify as women and men.

\begin{tabular}{|c|c|c|c|c|c|c|c|}
\hline \multirow{2}{*}{ Item } & \multirow{2}{*}{$U$} & \multirow{2}{*}{$p$} & \multirow{2}{*}{$d$} & \multicolumn{2}{|c|}{ Women $(n=166)$} & \multicolumn{2}{|c|}{ Men $(n=58)$} \\
\hline & & & & $M d n$ & $I Q R$ & $M d n$ & $I Q R$ \\
\hline Cleanser & 1920 & $<0.001$ & 0.59 & 4 & $3-5$ & 1 & $1-3$ \\
\hline Moisturizer on the face & 1437 & $<0.001$ & 0.70 & 5 & $4-5$ & 2 & $1-3$ \\
\hline Moisturizer on the body & 1700 & $<0.001$ & 0.64 & 3 & $2-4$ & 1 & $1-2$ \\
\hline Repairing/anti-ageing & 2080 & $<0.001$ & 0.57 & 2 & $1-4$ & 1 & 1 \\
\hline Sunscreen on the face & 2487.5 & $<0.001$ & 0.48 & 3 & $2-4$ & 2 & $2-3$ \\
\hline Sunscreen on the body & 2812.5 & $<0.001$ & 0.42 & 3 & $2-3$ & 2 & $2-3$ \\
\hline General skincare use & 1010 & $<0.001$ & 0.79 & 3.33 & $2.83-3.83$ & 2 & $1.33-2.33$ \\
\hline Frequency of sunscreen use on warm sunny days & 2983.5 & $<0.001$ & 0.38 & 4 & $3-5$ & 3 & $2-4$ \\
\hline Frequency of sunscreen use on cloudy days & 3196.5 & $<0.001$ & 0.32 & 2 & $1-3$ & 1 & $1-2$ \\
\hline Frequency of sunscreen use at the beach & 3209 & $<0.001$ & 0.32 & 5 & 5 & 4 & $4-5$ \\
\hline Frequency of sunscreen use during recreation & 3055.5 & $<0.001$ & 0.35 & 3 & $2-4$ & 2 & $1-3$ \\
\hline Frequency of sunscreen use during domestic chores & 3653 & 0.015 & 0.21 & 2 & $1-3$ & 2 & $1-2$ \\
\hline General sunscreen use & 2961.5 & $<0.001$ & 0.38 & 3 & $2.33-3.83$ & 2.42 & $2-2.83$ \\
\hline On the face on cloudy days (reapplication) & 3621 & 0.040 & 0.18 & 2 & $0-3$ & 0 & $0-2.75$ \\
\hline On a normal day (reapplication) & 3548 & 0.005 & 0.24 & 2 & $1-3$ & 1 & $1-2$ \\
\hline At the beach (reapplication) & 3589.5 & 0.011 & 0.21 & 3 & $3-4$ & 3 & $2-3$ \\
\hline When spending half a day or more outdoors (reapplicat.) & 3619.5 & 0.019 & 0.20 & 2 & $1-3$ & 2 & $1-3$ \\
\hline Skincare interest & 3066 & $<0.001$ & 0.35 & 4 & $4-5$ & 4 & $3-4$ \\
\hline Environmental attitude & 3680 & 0.011 & 0.20 & 5 & $4-5$ & 4 & $3.75-5$ \\
\hline $\begin{array}{l}\text { In addition to the origin of the ingredients, a sustainable way of } \\
\text { their production is also important. }\end{array}$ & 3385 & 0.004 & 0.23 & 5 & $4-5$ & 4 & $4-5$ \\
\hline $\begin{array}{c}\text { Good functionality/performance is what matters, not the origin of } \\
\text { the ingredients. }\end{array}$ & 3487.5 & 0.015 & 0.21 & 3 & $2-4$ & 3 & $3-4$ \\
\hline I tend to buy skincare products with ingredients of natural origin. & 3520.5 & 0.023 & 0.20 & 4 & $3-4$ & 3 & $2-4$ \\
\hline Bio-based purchase intention & 2911.5 & 0.035 & 0.19 & 4 & $3-4$ & 3 & $3-4$ \\
\hline Lignin familiarity & 2994 & 0.001 & 0.27 & 2 & $1-2$ & 2 & $1-3$ \\
\hline $\begin{array}{c}\text { Natural biopolymers can also be obtained from renewable sourced } \\
\text { leftover and waste from the industry }\end{array}$ & 2760 & 0.002 & 0.27 & 2 & $1-2$ & 2 & $1-3$ \\
\hline $\begin{array}{l}\text { Would you like to have more information about bio-based } \\
\text { ingredients for skincare products? }\end{array}$ & 2675 & 0.002 & 0.21 & 1 & 1 & 1 & $1-2$ \\
\hline
\end{tabular}

While there were some differences at the behavioral level, there were not many significant differences in the attitude, preference, or knowledge items. The most noticeable differences were in the frequency of use of various skincare products, including sunscreen in different situations. In general, respondents identifying as female were more likely to use sunscreen $\left(M_{f}=3.10, S D_{f}=0.99 ; M_{m}=2.42, S D_{m}=0.81\right)$ and other skincare products $\left(M_{f}=3.28, S D_{f}=0.78 ; M_{m}=1.93, S D_{m}=0.70\right)$ than their male counterparts, but there were no differences in sunscreen use for outdoor occupational tasks $(U=3810.5, p=0.407)$ and in the mountains $(U=3846, p=0.357)$ or in preference for type of sunscreen $(U=4147$, $p=0.407)$.

Women also reported having a greater interest in skincare $\left(U=3066, p<0.001 ; M d n_{f}=4\right.$, $\left.I Q R_{f}=4-5 ; M d n_{m}=4, I Q R_{m}=3-4\right)$ and were slightly more environmentally conscious. They rated higher the view that protecting and preserving the environment should take priority over economic growth and development $\left(U=3680, p=0.011 ; M d n_{f}=5, I Q R_{f}=4-5\right.$; $\left.M d n_{m}=4, I Q R_{m}=3.75-5\right)$ and that both the origin and sustainable production of ingredients are important $\left(U=3385, p=0.004 ; M d n_{f}=5, I Q R_{f}=4-5 ; M d n_{m}=4, I Q R_{m}=4-5\right)$, while they were less likely to agree that good functionality or performance is key, rather than the origin of ingredients $\left(U=3487.5, p=0.015 ; M d n_{f}=3, I Q R_{f}=2-4 ; M d n_{m}=3, I Q R_{m}=3-4\right)$. In addition, female respondents also tended to buy skincare products with ingredients of natural origin more often $\left(U=3520.5, p=0.023 ; M d n_{f}=4, I Q R_{f}=3-4 ; M d n_{m}=3\right.$, $\left.I Q R_{m}=2-4\right)$ and believe that they will continue to do so in the future $(U=2911.5, p=0.035$; $\left.M d n_{f}=4, I Q R_{f}=3-4 ; M d n_{m}=3, I Q R_{m}=3-4\right)$. Women scored significantly higher on the summary variable "Conscious buying behavior" $\left(U=3480, p=0.002 ; M d n_{f}=3.5, I Q R_{f}=3-4\right.$; $\left.M d n_{m}=3, I Q R_{m}=2.25-3.75\right)$.

Male respondents, on the other hand, were more familiar with lignin $(U=2994$, $\left.p=0.001 ; M d n_{f}=2, I Q R_{f}=1-2 ; M d n_{m}=2, I Q R_{m}=1-2\right)$ and the fact that natural biopolymers can also be derived from renewable sourced leftover and waste materials from industry $\left(U=2760, p=0.002 ; M d n_{f}=2, I Q R_{f}=1-2 ; M d n_{m}=2, I Q R_{m}=1-2\right)$ and were more interested in learning more about bio-based ingredients for skincare products $(U=2675, p=0.002$; $\left.M d n_{f}=1, I Q R_{f}=1 ; M d n_{m}=1, I Q R_{m}=1-2\right)$. However, there were no significant differences 
between genders in their desire to purchase a skincare product containing lignin $(U=4232.5$, $p=0.339$ ).

\section{Discussion}

As the consumption of skincare and sunscreen products increases, their environmental and health effects are compelling the development of more environmentally friendly alternatives. Lignin is an abundant and multifunctional natural polymer that can act as a broad-spectrum sunblock, antioxidant, and preservative and is usually a by-product of pulp manufacturing $[7,8]$, meaning it can replace and mitigate the impact of several synthetic ingredients in sunscreens. However, the aesthetic and functional performance of lignin-based sunscreens is limited in some respects, such as in terms of lower SPF and dark color as a result of pigmentation. This article, therefore, explored consumers familiarity, views, attitudes, and motivations towards lignin-based sunscreens and other sustainability-related issues and solutions in the context of skincare products.

In general, people are well informed about the effects of sun exposure, the current guidelines and benefits of sunscreens, and the environmental impact of synthetic skincare ingredients. Similar to other relevant research, most respondents considered bio-based ingredients to be safe, environmentally friendly, effective, of higher quality, and luxurious $[37,38]$. However, participants were less informed that some chemicals from skincare products tend to accumulate in living things and have already been detected in human fluids. One in three were unfamiliar with the possibilities of using natural biopolymers for sunscreens and that they can be derived from residual and waste materials from industry; however, most were interested in receiving more information on the topic of bio-based ingredients for skincare products. The results also show that most respondents are unfamiliar with lignin or have only heard of it but perceive it as a safe, renewable, natural, and affordable ingredient. Individuals who know more about other bio-based ingredients, their production and use, were also more likely to be familiar with lignin. While a quarter reported familiarity with lignin, the generalizability of this finding is questionable because the sample was not representative and included acquaintances of the authors. Three out of four people are open to trying a lignin-based sunscreen and were interested in a healthier and more environmentally friendly sunscreen option. This alternative is especially appealing to those who have a positive attitude toward bio-based ingredients, value the natural environment, and help protect it by purchasing greener skincare solutions.

Although the correlations were weak or modest at best, our results build on previous findings $[21,23,25-28,34-36]$ and show that knowledge, attitudes toward the environment and bio-based ingredients, past green purchasing behavior, and intention to buy green and lignin skincare are all positively related. However, contrary to our predictions, health consciousness had the weakest associations with sustainable purchasing behavior and intention to purchase and a non-significant relationship with knowledge and willingness to buy lignin-based sunscreens, suggesting that consumers may not perceive lignin-based sunscreens and other bio-based skincare products as healthier choices for them [31,32]. Another possible explanation for these results is the use of a single-item measurement rather than a validated scale. In contrast to previous research [35], we also found some differences related to gender. Not only were women more likely to use skincare and sunscreen and, as expected, more interested in skincare [11,12], but they also expressed more sustainable purchasing behavior and higher purchase intentions when buying skincare products compared to their male counterparts. However, those who identified as males and also individuals with higher education were more knowledgeable about lignin and other natural biopolymers and were also more interested in learning more about them.

To gain a deeper insight into consumers' thoughts and emotions about lignin, we identified several drivers of interest in purchasing a sunscreen based on lignin. In previous research, protection of the environment, health benefits, and product quality emerged as the three main motives for buying organic cosmetics [39]. The most frequently mentioned motives in our case were similarly related to protecting the environment, being an innova- 
tive solution by valorizing by-products, offering full protection against UVA and UVB rays, and being a healthier alternative to other ingredients commonly used in cosmetics. In fact, one in three participants mentioned avoiding some ingredients in their skincare, including preservatives (e.g., parabens), mineral and chemical UV filters (e.g., titanium dioxide and oxybenzone), surfactants (e.g., sodium laureth sulfate), and non-natural or animal-based ingredients, for which lignin can be a great alternative. One participant specifically mentioned that they consider conventional sunscreens harmful, and a lignin-based alternative would convince them to use this type of sun protection more often.

On the other hand, there were also some reservations about buying sunscreens based on lignin, the main reason being that an SPF value of 10 is too low to meet the needs of most participants. Similar to reports from previous research, people wear sunscreen most often at the beach, on warm sunny days, and during recreation, and they use a broad-spectrum sunscreen with an SPF of at least 15 or higher [13,14], with some having even higher expectations. This means that the lignin product cannot be used as a sunscreen for stronger sun exposure and for people who spend a lot of time outdoors or have sun-sensitive skin, such as people with fair skin and children. However, there are some alternative options. Participants mentioned that the limited SPF may not be an issue if the main purpose of the skincare product is different, such as moisturizing or anti-aging, meaning that the sunscreen acts as an addition or is intended for daily use on cloudy days when higher levels of protection are not desired.

Another barrier to the acceptance of a lignin-based sunscreen is its sensory characteristics, particularly its brown color. Although color, along with product novelty, turned out to be one of the least important features when choosing a skincare product, and some even believe that it makes the skin look tanner, people were still concerned about whether it would look uneven on the skin or whether the pigmentation would stain their clothes. Some were put off by the color of the product itself, stating that a brownish color would look unpleasant and unhygienic. These findings are consistent with previous studies that cited aesthetic and sensory properties as one of the most common reasons for infrequent sunscreen use [15]. However, the pigmentation opens up the possibility of developing and marketing the lignin product as a multifunctional tinted solution, bronzer, or other makeup product, especially for dark-skinned individuals, that provides sun protection in addition to coverage.

Another problem mentioned by the participants was that they did not have enough reliable information about lignin and its extraction, formulation, and stabilization, as well as the sustainability of all the processes involved in the development of the product. Since familiarity with the topic is associated with a greater chance of sustainable purchasing behavior, consumers need to be provided with transparent and detailed information when lignin is introduced to the market. Social media, television broadcasts, and research institutions have emerged as particularly useful communication channels that should be used to convey information and educate the public.

Finally, price appears to play a key role in skincare product purchase intentions. While some individuals felt that a lignin sunscreen would be an affordable option due to the wide availability of the biopolymer, others seemed to believe that it would be too expensive. Quality and price were found to be the most influential attributes in skincare product purchase decisions, which is reflected in both our results and previous research [33]. However, some people are willing to spend a little more on healthier and environmentally friendlier options. Affordable prices are therefore a great incentive to promote healthier and environmental friendlier purchasing decisions among people from all locations and incomes.

The findings of the study are limited by having used a convenience and non-representative sample. It includes a low number of subjects, many of whom are part of the authors' social networks, are highly educated, and are potentially more informed about lignin and have greater concerns about the environment than the general population. The sample also lacks individuals with darker skin types, who should be included in further studies, as they may 
have fewer concerns about a pigmented sunscreen. Another limitation of the study is its instrument and the lack of a validation study-although the survey was constructed by the authors based on an extensive literature review, it is not a validated instrument, i.e., it has not been psychometrically tested for validity, reliability, and sensitivity, and some constructs have low reliability. In addition, constructs such as attitude towards the environment, health consciousness, and interest in skincare were measured using single-item measures. In the future, valid multiple-item scales such as the Environmental Attitudes Inventory [18] should be used to capture such constructs. In addition, due to the high number of items measured, some results may be significant due to chance. As this is the first study to measure attitudes towards a lignin-based sunscreen, its scope was mainly exploratory and descriptive, but as the literature on this topic grows, more rigorous statistical methods need to be applied. Subsequently, the use of a theoretical framework such as Ajzen's Theory of Planned Behavior [41] would allow researchers to more systematically and comparably determine and understand the factors that influence consumers' green purchasing decisions. Finally, as this was a survey-based study, respondents formed their intentions to buy a lignin-based sunscreen based only on a description provided by the authors, meaning they were not familiar with the actual sensory characteristics of the product. Future studies should perform sensory panel studies to better understand how consumers feel about this innovation.

\section{Conclusions}

Overall, this work provides the first exploration of the consumers' perceptions of a lignin-based sunscreen in the context of other bio-based skincare ingredients, and it is the first study to examine lignin from a psychological perspective. The results of the study have implications for the development and marketing of an innovative and sustainable bio-based sunscreen prototype. While people seem intrigued by the idea of a sustainable and healthier sunscreen alternative, not many know about lignin. In addition to a positive attitude toward the environment and bio-based ingredients in general, sufficient information about the product is associated with a greater intention to buy it, so efforts should be made to educate the public about lignin and its production. We identified several concerns and opportunities that consumers view as significant in a lignin-based sunscreen and suggested ways to design a product that promotes healthier sun-related behaviors in a more targeted and sustainable manner. At this point, a sunscreen based on lignin cannot achieve a high enough SPF to offer adequate protection from UV rays on its own. For this reason, it is more realistic to create an all-in-one product that provides some coverage and protection from oxidative and sun damage.

Supplementary Materials: The following are available online at https://www.mdpi.com/article/ 10.3390/cosmetics8030078/s1, Document S1: Questionnaire in English, Document S2: Informed Consent Statement in English; Table S1: Socio-demographic data; Table S2: Data dictionary of numerical variables that were merged or single items representing a construct.

Author Contributions: Conceptualization, N.S., O.G., A.S. (Amy Simmons) and A.S. (Anna Sandak); methodology, N.S., O.G., A.S. (Amy Simmons) and A.S. (Anna Sandak); software, N.S.; validation, N.S., O.G., A.S. (Amy Simmons) and A.S. (Anna Sandak); formal analysis, N.S.; investigation, N.S., O.G., A.S. (Amy Simmons) and A.S. (Anna Sandak); resources, N.S., O.G., A.S. (Amy Simmons) and A.S. (Anna Sandak); data curation, N.S.; writing-original draft preparation, N.S. and O.G.; writing—review and editing, N.S., O.G., A.S. (Amy Simmons) and A.S. (Anna Sandak); visualization, N.S.; supervision, A.S. (Anna Sandak); project administration, N.S., O.G., A.S. (Amy Simmons) and A.S. (Anna Sandak); funding acquisition, N.S., O.G., A.S. (Amy Simmons) and A.S. (Anna Sandak). All authors have read and agreed to the published version of the manuscript.

Funding: The study is part of the InnoRenew project (Horizon2020 Widespread-2-Teaming program, grant agreement 739574) and was supported by the Republic of Slovenia (investment funding from the Republic of Slovenia and the European Regional Development Fund) and infrastructural ARRS program IO-0035. Oihana Gordobil is grateful for the financial support received from the European 
Union's Horizon 2020 research and innovation program under the Marie Skłodowska-Curie Action for development of the BIO4CARE project (grant number 101023389).

Institutional Review Board Statement: Ethical review and approval were waived for this study as it did not include any ethical issues.

Informed Consent Statement: Informed consent was obtained from all subjects involved in the study.

Data Availability Statement: The data presented in this study are available in a Zenodo open data repository at https:/ / zenodo.org/record/5126564\#.YPpx2Y4zYuU.

Conflicts of Interest: The authors declare no conflict of interest.

\section{References}

1. Chouhan, N.; Vig, H.; Deshmukh, R. Cosmetics Market by Category, Gender, and Distribution Channel: Global Opportunity Analysis and Industry Forecast, 2021-2027; Allied Market Research: Maharashtra, India, 2021.

2. Juliano, C.; Magrini, G.A. Cosmetic ingredients as emerging pollutants of environmental and health concern. A mini-review. Cosmetics 2017, 4, 11. [CrossRef]

3. Shinn, H. The Effects of Ultraviolet Filters and Sunscreen on Corals and Aquatic Ecosystems: Bibliography; National Oceanic and Atmospheric Administration: Washington, DC, USA, 2019; ISBN 0024401502277. Available online: https://10.25923/hhrp-xq11 (accessed on 7 June 2021).

4. Franco, L.; Marchena, A.; Rodríguez, A. Skin Health Properties of Lycopene and Melatonin. J. Dermatol. Ski. Sci. 2021, 3, 26-29. [CrossRef]

5. $\quad$ Österberg, M.; Sipponen, M.H.; Mattos, B.D.; Rojas, O.J. Spherical lignin particles: A review on their sustainability and applications. Green Chem. 2020, 22, 2712-2733. [CrossRef]

6. Bajwa, D.S.; Pourhashem, G.; Ullah, A.H.; Bajwa, S.G. A concise review of current lignin production, applications, products and their environment impact. Ind. Crops Prod. 2019, 139, 111526. [CrossRef]

7. Qian, Y.; Qiu, X.; Zhu, S. Sunscreen performance of lignin from different technical resources and their general synergistic effect with synthetic sunscreens. ACS Sustain. Chem. Eng. 2016, 4, 4029-4035. [CrossRef]

8. Gordobil, O.; Olaizola, P.; Banales, J.M.; Labidi, J. Lignins from agroindustrial by-products as natural ingredients for cosmetics: Chemical structure and in vitro sunscreen and cytotoxic activities. Molecules 2020, 25, 1131. [CrossRef] [PubMed]

9. Widsten, P.; Tamminen, T.; Liitiä, T. Natural Sunscreens Based on Nanoparticles of Modified Kraft Lignin (CatLignin). ACS Omega 2020, 5, 13438-13446. [CrossRef]

10. Popovic, I.; Bossink, B.A.G.; van der Sijde, P.C. Factors influencing consumers' decision to purchase food in environmentally friendly packaging: What do we know and where do we go from here? Sustainability 2019, 11, 7197. [CrossRef]

11. Holman, D.M.; Berkowitz, Z.; Guy, G.P.; Hawkins, N.A.; Saraiya, M.; Watson, M. Patterns of sunscreen use on the face and other exposed skin among US adults. J. Am. Dermatol. 2015, 73, 83-92.e1. [CrossRef]

12. Falk, M.; Anderson, C.D. Influence of age, gender, educational level and self-estimation of skin type on sun exposure habits and readiness to increase sun protection. Cancer Epidemiol. 2013, 37, 127-132. [CrossRef]

13. Cervinka, R.; Moshammer, H. Gender aspects of recreational sun-protective behavior: Results of a representative, populationbased survey among Austrian residents. Photodermatol. Photoimmunol. Photomed. 2015, 32, 11-21. [CrossRef]

14. Cercato, M.C.; Ramazzotti, V.; Sperduti, I.; Asensio-Pascual, A.; Ribes, I.; Guillén, C.; Nagore, E. Sun Protection Among Spanish Beachgoers: Knowledge, Attitude and Behaviour. J. Cancer Educ. 2015, 30, 4-11. [CrossRef]

15. Hewitt, J.P. Sunscreen Formulation: Optimising Aesthetic Elements for Twenty-First-Century Consumers. In Principles and Practice of Photoprotection; Wang, S.Q., Lim, H.W., Eds.; Springer International Publishing: Cham, Switzerland, 2016; pp. 289-302. [CrossRef]

16. Ajzen, I.; Fishbein, M. Attitudes and the Attitude-Behavior Relation: Reasoned and Automatic Processes. Eur. Rev. Soc. Psychol. 2000, 11, 1-33. [CrossRef]

17. Ajzen, I.; Cote, N.G. Attitudes and the prediction of behavior. In Attitudes and Attitude Change; Crano, W.D., Prislin, R., Eds.; Psychology Press: Hove, UK, 2008; pp. 289-311.

18. Milfont, T.L.; Duckitt, J. The environmental attitudes inventory: A valid and reliable measure to assess the structure of environmental attitudes. J. Environ. Psychol. 2010, 30, 80-94. [CrossRef]

19. Jaiswal, D.; Kant, R. Green purchasing behaviour: A conceptual framework and empirical investigation of Indian consumers. J. Retail. Consum. Serv. 2018, 41, 60-69. [CrossRef]

20. Kaynak, R.; Ekşi, S. Effects of Personality, Environmental and Health Consciousness on Understanding the Anti-consumptional Attitudes. Procedia-Soc. Behav. Sci. 2014, 114, 771-776. [CrossRef]

21. Liobikienè, G.; Bernatonienè, J. Why determinants of green purchase cannot be treated equally? The case of green cosmetics: Literature review. J. Clean. Prod. 2017, 162, 109-120. [CrossRef]

22. Hall, M.C.; Hall, M.C. The Marketing of Organic Products: An Instrumental/Symbolic Perspective. J. Food Prod. Mark. 2008, 4446, 1-11. [CrossRef] 
23. Yadav, R.; Pathak, G.S. Intention to purchase organic food among young consumers: Evidences from a developing nation. Appetite 2016, 96, 122-128. [CrossRef]

24. Hao, Z.; Chenyue, Q. Impact of environmental and health consciousness on ecological consumption intention: The moderating effects of haze and self-competence. J. Consum. Aff. 2021, 1-14. [CrossRef]

25. Alzubaidi, H.; Slade, E.L.; Dwivedi, Y.K. Examining antecedents of consumers' pro-environmental behaviours: TPB extended with materialism and innovativeness. J. Bus. Res. 2021, 122, 685-699. [CrossRef]

26. Kim, H.Y.; Chung, J.E. Consumer purchase intention for organic personal care products. J. Consum. Mark. 2011, 28 , 40-47. [CrossRef]

27. Sadiq, M.; Adil, M.; Paul, J. An innovation resistance theory perspective on purchase of eco-friendly cosmetics. J. Retail. Consum. Serv. 2021, 59, 102369. [CrossRef]

28. Wijekoon, R.; Sabri, M.F. Determinants that influence green product purchase intention and behavior: A literature review and guiding framework. Sustainability 2021, 13, 6219. [CrossRef]

29. Hsu, C.L.; Chang, C.Y.; Yansritakul, C. Exploring purchase intention of green skincare products using the theory of planned behavior: Testing the moderating effects of country of origin and price sensitivity. J. Retail. Consum. Serv. 2017, 34, 145-152. [CrossRef]

30. Chin, J.; Jiang, B.C.; Mufidah, I.; Persada, S.F.; Noer, B.A. The investigation of consumers' behavior intention in using green skincare products: A pro- environmental behavior model approach. Sustainability 2018, 10, 3922. [CrossRef]

31. Shimul, A.S.; Cheah, I.; Khan, B.B. Investigating Female Shoppers' Attitude and Purchase Intention toward Green Cosmetics in South Africa. J. Glob. Mark. 2021, 1-20. [CrossRef]

32. Tarkiainen, A.; Sundqvist, S. Subjective norms, attitudes and intentions of Finnish consumers in buying organic food. Br. Food J. 2005, 107. [CrossRef]

33. Moser, A.K. Consumers' purchasing decisions regarding environmentally friendly products: An empirical analysis of German consumers. J. Retail. Consum. Serv. 2016, 31, 389-397. [CrossRef]

34. Joshi, Y.; Rahman, Z. Factors Affecting Green Purchase Behaviour and Future Research Directions. Int. Strateg. Manag. Rev. 2015, 3, 128-143. [CrossRef]

35. Hojnik, J.; Ruzzier, M.; Ruzzier, M.K. Transition towards sustainability: Adoption of eco-products among consumers. Sustainability 2019, 11, 4308. [CrossRef]

36. Hojnik, J.; Ruzzier, M.; Manolova, T.S. Sustainable development: Predictors of green consumerism in Slovenia. Corp. Soc. Responsib. Environ. Manag. 2020, 27, 1695-1708. [CrossRef]

37. Lin, Y.; Yang, S.; Hanifah, H.; Iqbal, Q. An Exploratory Study of Consumer Attitudes Toward Green Cosmetics in the UK Market. Adm. Sci. 2018, 8, 71. [CrossRef]

38. Yano, Y.; Kato, E.; Ohe, Y.; Blandford, D. Examining the opinions of potential consumers about plant-derived cosmetics: An approach combining word association, co-occurrence network, and multivariate probit analysis. J. Sens. Stud. 2019, 34 , e12484. [CrossRef]

39. Cervellon, M.-C.; Rinaldi, M.-J.; Wernerfelt, A.-S. How Green is Green? Consumers' understanding of green cosmetics and their certifications. In Proceedings of the 10th International Marketing Trends Conference, Paris, France, $20-22$ January 2011.

40. Weijters, B.; Baumgartner, H.; Schillewaert, N. Reversed item bias: An integrative model. Psychol. Methods 2013, 18, 320-334. [CrossRef] [PubMed]

41. Ajzen, I. The theory of planned behavior. Organ. Behav. Hum. Decis. Process. 1991, 50, 179-211. [CrossRef] 